\title{
Kaderisasi dan Peningkatan Kemampuan Pelatih Karawitan di Kelompok Seni Ngudi Laras, Watu Lumbung, Kadiluwih Salam, Magelang
}

\author{
Anon Suneko ${ }^{1}$, Agung Sutrisno ${ }^{2}$ \\ ${ }^{1,2}$ Jurusan Karawitan, Fakultas Seni Pertunjukan \\ Institut Seni Indonesia Yogyakarta \\ Jalan Parangtritis Km 6,5, Sewon, Bantul, Daerah Istimewa Yogyakarta 55188 \\ No.Hp.: ${ }^{1}+628406404022$, E-mail: anon.suneko@isi.ac.id
}

\begin{abstract}
Abstrak
Seni budaya Indonesia yang beragam dalam perkembangannya membutuhkan penguatan, pengembangan, dan inovasi agar tetap diterima dan berkembang kepada generasi penerus bangsa. Pelestarian budaya diupayakan melalui berbagai kegiatan, salah satunya adalah penyuluhan seni karena dalam penyuluhan terdapat proses yang melibatkan langsung antara pemangku kepentingan, akademisi, dan masyarakat secara langsung. Karawitan menjadi salah satu kesenian yang tumbuh dan berkembang dalam tradisi yang khas dan menarik. Tujuan dari penyuluhan seni di bidang karawitan dengan objek kelompok seni Ngudi Laras melalui kaderisasi pelatih, peningkatan kemampuan pelatih, pendampingan dan pelatihan kerawitan, serta publikasi kegiatan sanggar. Metode penyuluhan seni ini menggunakan metode penyuluhan langsung (direct communications), yang digunakan pada waktu berhadapan muka ke muka dengan sasarannya dan berdialog dengan pelatih dan anggotanya. Metode yang langsung ini dianggap lebih efektif, meyakinkan, dan mengakrabkan hubungan antara penyuluh dan sasaran. Penyuluhan seni dengan tajuk "Kaderisasi dan Peningkatan Kemampuan Pelatih Karawitan di Kelompok Seni Ngudi Laras, Watu Lumbung, Kadiluwih, Salam, Magelang” memberikan penerangan atau informasi agar hal-hal yang tadinya belum diketahui ataupun dipecahkan kaitannya dengan problematika di dalamnya agar segera menemukan jalan keluar yang terbaik sehingga kesinambungan aktivitas sanggar tersebut bisa berjalan secara terus-menerus dan mengalami peningkatan yang signifikan.
\end{abstract}

Kata kunci: karawitan, penyuluhan, seni, kaderisasi

\section{Leadership and Skill Improvement Training for Karawitan Trainer in Ngudi Laras Arts Group, Watu Lumbung, Kadiluwih, Salam, Magelang}

\section{Abstract}

Indonesian arts are very diverse in its development and are in need of support, growth, and innovation so that it may be accepted and further grown by the next generation. Heritage conservation is done through various activities such as training, in which actively involves a range of those in authority, academicians, and lay people. Karawitan (gamelan musical) is one of the heritage that has grown into its own unique tradition. The purpose of this training at Ngudi Laras is the leadership, guidance, and skill training for the karawitan trainers, then followed by the publication of the workshop's routine. The method done in this training is through direct communication with face to face dialog from trainer to members. This method is chosen for its efficiency in assuring and bridging the relationship gap between the two. The training titled "Leadership and Skill Improvement Training for Karawitan Trainer in Ngudi Laras Arts Group, Watu Lumbung, Kadiluwih, Salam, Magelang” gives insight or information about things previously not published for public to solve the problem never addressed before so that the workshop longevity can go continuously and experiences a significant growth.

Keywords: karawitan, training, arts, leadership 


\section{PENDAHULUAN}

Kelompok Seni Ngudi Laras merupakan sebuah kelompok kesenian yang berasal dari Watu Lumbung, Kadiluwih, Salam, Magelang. Kelompok seni ini memiliki visi berperan aktif dalam melestarikan budaya tradisi Jawa khususnya seni karawitan yang ditujukan kepada masyarakat seluas-luasnya. Anggota kelompok seni yang terdiri dari pelaku seni senior baik wiraswara, penabuh, maupun pelatih berkeinginan untuk bersamasama memperkuat kelompok ini untuk berperan membantu pemerintah dalam upaya pelestarian seni karawitan. Kesinambungan kegiatan ini sangat membutuhkan campur tangan baik pemerintah maupun lembaga pendidikan tinggi seni melalui pembinaan, kaderisasi pelatih, dan peningkatan kemampuan para pelatihnya sehingga kelompok ini dapat mengoptimalkan potensi yang dimiliki. Dengan demikian, ke depannya kelompok ini dapat menjadi pioner di lingkungannya untuk mendukung pelestarian seni karawitan khususnya di Watu Lumbung, Kadiluwih, Salam Magelang.

Kelompok Seni Ngudi Laras telah memiliki agenda latihan rutin setiap satu minggu sekali. Sanggar ini belum memiliki pelatih tetap khususnya untuk karawitan remaja atau karangtaruna. Hingga saat ini, latihan karawitan baik itu anak-anak maupun dewasa masih tetap berjalan meskipun keterbatasan materi/gending dan SDM pelatih seringkali menjadi faktor yang menyebabkan menurunnya semangat berlatih karawitan. Uraian tersebut menunjukkan bahwa keberadaaan Kelompok Seni Ngudi Laras hingga saat ini belum bisa lepas dari permasalahan yang dihadapi. Problematika ini baik secara langung maupun tidak langsung telah menghambat kelangsungan aktivitas kelompok seni tersebut. Secara lebih luas, hal ini akan berpengaruh pada upaya pelestarian seni karawitan khususnya di Watu Lumbung, Kadiluwih, Salam, Magelang.

Kendala atau permasalahan yang dihadapi Kelompok Seni Ngudi Laras memerlukan menyikapan yang serius demi mempertahankan kesinambungan upaya pelestarian budaya melalui sektor karawitan sebagai bidang yang diandalkan oleh kelompok tersebut. Adapun beberapa solusi yang dapat ditawarkan adalah sebagai berikut.

1. Kaderisasi pelatih

Kelangsungan kegiatan pelatihan karawitan di Kelompok Seni Ngudi Laras saat ini sangat tergantung pada salah satu anggota senior saja sehingga perlu dilakukan kaderisasi pelatih/guru karawitan yang lebih menekankan peran aktif kalangan generasi muda dalam andil yang lebih vital untuk menjaga kelangsungan kegiatan pelatihan karawitan. Kaderisasi ini akan menanamkan kesadaran akan pentingnya regenerasi pelatih dan kepercayaan diri kepada generasi muda sanggar sehingga mulai tergugah untuk berkonstribusi secara lebih total terhadap Kelompok Seni Ngudi Laras.

2. Peningkatan kemampuan pelatih

Upaya ini dilakukan untuk membekali calon-calon pelatih di Kelompok Seni Ngudi Laras dengan pengetahuan dan keterampilan sesuai dengan kebutuhan yang ingin dipenuhi dan visi sanggar yang ingin dicapai. Materi pembekalan pelatih ini akan disesuaikan sedemikian rupa dengan perkembangan dunia karawitan serta kemajuan pola pikir masyarakat masa kini sehingga hal ini diharapkan dapat mendongkrak mutu kegiatan sanggar seni yang jauh lebih nyata, semakin kreatif, dan inovatif kelak di kemudian hari. 
3. Pendampingan dan pelatihan karawitan Pendampingan dan pelatihan karawitan ini perlu sekali dilakukan untuk memberi wacana dan gambaran secara nyata terhadap anggota Kelompok Seni Ngudi Laras mengenai strategi pembelajaran yang efektif. Kegiatan ini juga diharapkan mampu meningkatkan pengetahuan, kemampuan, dan keterampilan anggota sanggar dalam olah seni karawitan. Pelatihan karawitan akan menggunakan materi gending/lagu sesuai dengan kebutuhan serta beberapa materi gaya baru untuk membuka wacana serta menginspirasi kreasi seni karawitan masa kini di Kelompok Seni Ngudi Laras.

4. Publikasi kegiatan sanggar

Publikasi kegiatan sanggar diperlukan untuk memperluas jaringan kerja sama Kelompok Seni Ngudi Laras dengan pihak luar, baik itu masyarakat, lembaga pendidikan, maupun lembaga pemerintah. Secara lebih jauh, kerja sama yang dibina akan memberikan manfaat yang positif terhadap kedua belah pihak. Hal ini menjadi salah satu upaya sanggar untuk menarik publik dan pemerintah untuk melirik, simpatik, dan peduli terhadap keberadaan Kelompok Seni Ngudi Laras.

Solusi-solusi tersebut akan direalisasikan melalui beberapa kegiatan yang dirancang sedemikian rupa. Dengan demikian, permasalahan yang dihadapi Kelompok Seni Ngudi Laras akan segera teratasi dengan baik.

\section{METODE PENGABDIAN}

Berdasarkan tekniknya, penyuluhan seni ini menggunakan metode penyuluhan langsung (direct communications). Metode langsung digunakan waktu berhadapan muka ke muka dengan sasarannya dan berdialog dengan pelatih dan anggotanya. contohnya demonstrasi, ceramah, kursus, dan obrolan sore. Metode langsung ini dianggap lebih efektif, meyakinkan, dan mengakrabkan hubungan antara penyuluh dan sasaran.

\section{HASIL DAN PEMBAHASAN}

a. Objek Penyuluhan

1. Khalayak Sasaran

Sesuai dengan program kerja yang telah disusun, penyuluhan seni yang dilaksanakan selama kurang lebih dua bulan di sanggar Kelompok Seni Ngudi Laras ini memiliki khalayak sasaran yang menjadi objek di dalamnya. Menyikapi tentang pentingnya peningkatan mutu serta pentingnya kaderisasi pelatih kelompok seni Ngudi Laras, penyuluhan ini ditujukan kepada anggota sanggar utamanya para pelatih kegiatan kesenian. Keseluruhan anggota dan pelatih sejumlah 20 orang telah mengikuti penyuluhan seni dalam kurun waktu 2 Maret s.d. 30 Agustus 2020 dengan baik.

\section{Tempat Kegiatan}

Penyuluhan seni tentang peningkatan kualitas pelatih ini diadakan di sanggar Kelompok Seni Ngudi Laras yang beralamatkan di Watu Lumbung, Kadiluwih, Salam, Magelang. Basecamp Kelompok Seni Ngudi Laras terletak di kediaman Bapak Agus, yang merupakan salah satu anggota Kelompok Seni Ngudi Laras karena letak gamelan yang berada di tengah Dusun Watu Lumbung sehingga menarik warga sekitar untuk ikut serta dalam belajar karawitan.

\section{Tujuan}

Secara umum penyuluhan ini memiliki tujuan: (a) memberikan penerangan atau informasi kepada masyarakat Kelompok Seni Ngudi Laras agar hal-hal yang tadinya 
belum diketahui ataupun dipecahkan kaitannya dengan problematika di dalamnya agar segera menemukan jalan keluar yang terbaik sehingga kesinambungan aktivitas kelompok seni tersebut bisa berjalan secara terus-menerus dan mengalami peningkatan yang signifikan; (b) mempelajari sistem dan perubahan pada individu serta masyarakat Kelompok Seni Ngudi Laras agar terwujud perubahan yang lebih sesuai dengan apa yang diharapkan sanggar itu sendiri; dan (c) memberdayakan dan memperkuat kemampuan Kelompok Seni Ngudi Laras melalui proses belajar bersama yang partisipafif agar terjadi perubahan perilaku pada diri setiap individu dan masyarakatnya untuk mengelola kegiatan yang semakin produktif dan efisien, demi terwujudnya kehidupan sanggar yang lebih baik dan sejahtera secara berkelanjutan.

\section{Manfaat}

Penyuluhan ini akan memberikan manfaat kepada beberapa pihak, yang secara langsung maupun tidak langsung memperoleh manfaat dari penyuluhan ini, yaitu dosen penyuluh, mitra penyuluhan, dan pemerintah daerah setempat. Manfaat penyuluhan bagi dosen: (a) memberikan pangalaman baru dalam proses pembelajaran di luar kampus baik bagi dosen maupun mahasiswa; (b) memberikan pengalaman bagi dosen, mahasiswa, dan peserta penyuluhan untuk terlibat dalam sistem dan proses perubahan yang terjadi dalam masyarakat; (c) meningkatkan kemampuan dosen dalam kapasitasnya sebagai pengajar, praktisi, dan kreator dalam proses penyuluhan; dan (d) meningkatkan kemampuan mahasiswa dalam kapasitasnya sebagai agen perubahan, praktisi, dan kreator seni dalam proses penyuluhan.

Manfaat penyuluhan bagi kelompok seni: (a) memberikan pengalaman baru dalam proses pembelajaran yang dilakukan secara sistematis oleh kalangan akademisi; (b) memberikan pengalaman secara langsung dalam sistem dan proses perubahan sanggar seni kearah yang lebih baik; dan (c) meningkatkan kemampuan sanggar sebagai pihak yang memiliki modal, keinginan/inisiatif, ide kreatif, dan potensi.

Manfaat penyuluhan bagi pemerintah: (a) pemberdayaan potensi masyarakat akan berjalan lebih baik; (b) komunikasi pembangunan masyarakat melalui sektor seni karawitan akan berlangsung semakin baik, dan (c) pemasaran sosial masyarakat akan lebih mengenai sasaran dan berorientasi pada keinginandan tujuan yang ingin dicapai oleh masyarakat.

\section{Waktu Pelaksanaan Kegiatan \\ Kaderisasi dan peningkatan} kemampuan pelatih karawitan di Kelompok Seni Ngudi Laras ini dilakukan sesuai jadwal yang telah disusun oleh penulis pada tahap awal persiapan penyuluhan.

Tabel 1 Jadwal Pelaksanaan Kegiatan Penyuluhan Seni

\begin{tabular}{l|l|l|l|l}
\hline No. & Hari \& Tanggal & Jam & Materi & Tempat \\
\hline 1. & 3 Maret 2020 & 19.00 WIB & $\begin{array}{l}\text { Presentasi tentang karawitan, sejarah, } \\
\text { dan perkembangannya }\end{array}$ & $\begin{array}{l}\text { Kelompok Seni } \\
\text { Ngudi Laras }\end{array}$ \\
\hline
\end{tabular}




\begin{tabular}{|c|c|c|c|c|}
\hline 2. & 5 Maret 2020 & $19.00 \mathrm{WIB}$ & $\begin{array}{l}\text { Pengenalan tentang referensi } \\
\text { gending/lagu dan wawasan mengenai } \\
\text { karawitan kreasi kepada remaja dan } \\
\text { anak-anak }\end{array}$ & $\begin{array}{l}\text { Kelompok Seni } \\
\text { Ngudi Laras }\end{array}$ \\
\hline 3. & 12 Maret 2020 & $19.00 \mathrm{WIB}$ & $\begin{array}{l}\text { Kiat-kiat dalam pembelajaran karawitan } \\
\text { remaja dan anak-anak }\end{array}$ & $\begin{array}{l}\text { Kelompok Seni } \\
\text { Ngudi Laras }\end{array}$ \\
\hline 4. & 19 Juli 2020 & $19.00 \mathrm{WIB}$ & Latihan gending/lagu dolanan anak & $\begin{array}{l}\text { Kelompok Seni } \\
\text { Ngudi Laras }\end{array}$ \\
\hline 5. & 28 Juli 2020 & $16.00 \mathrm{WIB}$ & $\begin{array}{l}\text { Pelatihan materi gending karawitan } \\
\text { tingkat menengah }\end{array}$ & $\begin{array}{l}\text { Kelompok Seni } \\
\text { Ngudi Laras }\end{array}$ \\
\hline 6. & 3 Agustus 2020 & $19.00 \mathrm{WIB}$ & $\begin{array}{l}\text { Pelatihan materi gending karawitan } \\
\text { tingkat menengah }\end{array}$ & $\begin{array}{l}\text { Kelompok Seni } \\
\text { Ngudi Laras }\end{array}$ \\
\hline 7. & 5 Agustus 2020 & $16.00 \mathrm{WIB}$ & $\begin{array}{l}\text { Pelatihan materi gending karawitan } \\
\text { tingkat menengah }\end{array}$ & $\begin{array}{l}\text { Kelompok Seni } \\
\text { Ngudi Laras }\end{array}$ \\
\hline 8. & 7 Agustus 2020 & $19.00 \mathrm{WIB}$ & $\begin{array}{l}\text { Pelatihan materi gending karawitan } \\
\text { tingkat menengah }\end{array}$ & $\begin{array}{l}\text { Kelompok Seni } \\
\text { Ngudi Laras }\end{array}$ \\
\hline 9. & 9 Agustus 2020 & $16.00 \mathrm{WIB}$ & $\begin{array}{l}\text { Pelatihan materi gending karawitan } \\
\text { tingkat lanjut }\end{array}$ & $\begin{array}{l}\text { Kelompok Seni } \\
\text { Ngudi Laras }\end{array}$ \\
\hline 10. & 12 Agustus 2020 & $19.00 \mathrm{WIB}$ & $\begin{array}{l}\text { Pelatihan materi gending karawitan } \\
\text { tingkat lanjut }\end{array}$ & $\begin{array}{l}\text { Kelompok Seni } \\
\text { Ngudi Laras }\end{array}$ \\
\hline 11. & 23 Agustus 2020 & $19.00 \mathrm{WIB}$ & $\begin{array}{l}\text { Pelatihan materi gending karawitan } \\
\text { tingkat lanjut }\end{array}$ & $\begin{array}{l}\text { Kelompok Seni } \\
\text { Ngudi Laras }\end{array}$ \\
\hline 12. & 25 Agustus 2020 & $10.00 \mathrm{WIB}$ & Evaluasi, kesan, dan pesan & $\begin{array}{l}\text { Kelompok Seni } \\
\text { Ngudi Laras }\end{array}$ \\
\hline
\end{tabular}

\section{Daftar Peserta}

Penyuluhan ini akan melibatkan 20 penyuluhan yang diadakan di sanggar peserta dewasa. Berikut ini nama-nama peserta Kelompok Seni Ngudi Laras.

Tabel 2 Nama Peserta Penyuluhan Seni

\begin{tabular}{cl}
\hline No. & \multicolumn{2}{c}{ Nama } \\
\hline 1. & Arif Ridwanto \\
\hline 2. & Triwiyanto \\
\hline 3. & Angga Yoga \\
\hline 4. & Raihan husein \\
\hline 5. & Silo
\end{tabular}




\begin{tabular}{ll}
\hline 6. & Ari \\
\hline 7. & Afit Choirudin \\
\hline 8. & Muhamad Fandi \\
\hline 9. & Vina \\
\hline 10. & Rubiyo \\
\hline 11. & Sutiman \\
\hline 12. & Muhamad Fandi \\
\hline 13. & Vina \\
\hline 14. & Rubiyo \\
\hline 15. & Sutiman \\
\hline 16. & Muhamad Fandi \\
\hline 17. & Vina \\
\hline 18. & Rubiyo \\
\hline 19. & Sutiman \\
\hline 20. & Muhamad Fandi
\end{tabular}

B. Kegiatan Penyuluhan

1. Materi Penyuluhan

Dalam penyusunan materi penyuluhan, penyuluh melakukan penelitian sederhana secara kualitatif. Menurut Sugiyono (2012), ada dua hal yang memengaruhi kualitas data penelitian, yaitu insitrumen penelitian dan kualitas pengumpulan data. Data yang dibutuhkan dalam penyuluhan seni adalah mengenai data internal dan eksternal kelompok seni sendiri. Dalam penelitian sederhananya, pelatih menjadi objek utama yang harus dikaji agar menghasilkan tujuan yang diharapkan dari penyuluhan seni. Materi yang dibuat dari kebutuhan target sasaran terutama pelatih seni dibuat dan di rancang agar ideal dan efektif.

Penyuluhan seni tentang peningkatan mutu kualitas pelatih di sanggar Kelompok Seni Ngudi Laras dilaksanakan melalui serangkaian kegiatan terprogram dalam 12 kali tatap muka antara penyuluh dan pelatih beserta anggotanya. Selama melakukan penyuluhan, penulis memberikan materi sesuai dengan kebutuhan sanggar dan tersusun dalam jadwal kegiatan penyuluhan.

Tabel 3 Materi Penyuluhan Seni

\begin{tabular}{cll}
\hline Pertemuan ke- & \multicolumn{1}{c}{ Materi } & Keterangan \\
\hline 1 & Karawitan, sejarah, dan & Penulis memberikan ceramah \\
perkembangannya & mengenai pengertian \\
& & karawitan, awal mula, dan \\
& & perkembangannya \\
\hline 2 & Referensi gending/lagu serta & Penulis memberikan referensi \\
& wawasan mengenai karawitan & kepada peserta tentang \\
& kreasi kepada pemula. & beberapa bentuk karawitan \\
& & kreasi untuk remaja dan anak- \\
& & anak. Referensi diberikan \\
\hline
\end{tabular}


melalui beberapa media baik

audio, video, maupun

demonstrasi/peragaan secara

langsung

\begin{tabular}{|c|c|c|}
\hline & & langsung \\
\hline 3 & $\begin{array}{l}\text { Kiat-kiat dalam pembelajaran } \\
\text { karawitan pemula. }\end{array}$ & $\begin{array}{l}\text { Penulis memberikan strategi- } \\
\text { strategi pembelajaran gamelan } \\
\text { yang dirasa sesuai dengan } \\
\text { situasi dan kondisi sanggar } \\
\text { Kelompok Seni Ngudi Laras. }\end{array}$ \\
\hline 4 & Gending/lagu dolanan & $\begin{array}{l}\text { Sluku-Sluku Bathok versi tradisi } \\
\text { (konvensional) }\end{array}$ \\
\hline 5 & $\begin{array}{l}\text { Aransemen gending/lagu } \\
\text { dolanan }\end{array}$ & $\begin{array}{l}\text { Penulis memberikan contoh } \\
\text { aransemen sederhana dari lagu } \\
\text { Sluku-Sluku Bathok }\end{array}$ \\
\hline 6 & Tembang dolanan Jawa & $\begin{array}{l}\text { Penulis mengajak pelatih dan } \\
\text { peserta untuk berlatih vokal } \\
\text { pada tembang Cublak-Cublak } \\
\text { Suweng. Hal ini ditujukan untuk } \\
\text { memberikan keseimbangan } \\
\text { olah vokal dan keterampilan } \\
\text { menabuh bagi para peserta } \\
\text { penyuluhan. }\end{array}$ \\
\hline 7 & $\begin{array}{l}\text { Aransemen gending/lagu } \\
\text { dolanan }\end{array}$ & $\begin{array}{l}\text { Penulis memberikan contoh } \\
\text { aransemen sederhana dari lagu } \\
\text { Cublak-Cublak suweng. }\end{array}$ \\
\hline 8 & $\begin{array}{l}\text { Dasar olah komposisi } \\
\text { karawitan sederhana }\end{array}$ & $\begin{array}{l}\text { Penulis menciptakan komposisi } \\
\text { karawitan sederhana untuk } \\
\text { anak-anak dengan judul " } a-i-u- \\
e-o \text { ”, dan melatihkannya } \\
\text { kepada para pelatih serta } \\
\text { anggota sebagai bekal dalam } \\
\text { mengembangkan dan } \\
\text { memperkaya materi gending- } \\
\text { gending bagi sanggar } \\
\text { Kelompok Seni Ngudi Laras ke } \\
\text { depannya }\end{array}$ \\
\hline 9 & $\begin{array}{l}\text { Mengemas sajian outbond } \\
\text { karawitan }\end{array}$ & $\begin{array}{l}\text { Penulis memberikan ceramah } \\
\text { yang berisi pengemasan seni } \\
\text { karawitan dalam hubungannya } \\
\text { sebagai sajian seni wisata di } \\
\text { sanggar Kelompok Seni Ngudi } \\
\text { Laras. }\end{array}$ \\
\hline 10 & $\begin{array}{l}\text { Tata teknik pementasan seni } \\
\text { pertunjukan }\end{array}$ & $\begin{array}{l}\text { Penulis memberikan ceramah } \\
\text { yang berisi tata teknik }\end{array}$ \\
\hline
\end{tabular}


pementasan seni karawitan

dalam konteks sajian seni

wisata di sanggar Kelompok

Seni Ngudi Laras

\begin{tabular}{|c|c|c|}
\hline 11 & $\begin{array}{l}\text { Konser karawitan hasil } \\
\text { pelatihan }\end{array}$ & $\begin{array}{l}\text { Pementasan karawitan } \\
\text { Kelompok Seni Ngudi Laras } \\
\text { dilakukan secara tertutup } \\
\text { dikarenakan sedang pandemi } \\
\text { Covid-19 }\end{array}$ \\
\hline 12 & Evaluasi, kesan, dan pesan & $\begin{array}{l}\text { Penulis mengadakan } \\
\text { pertemuan terakhir dan } \\
\text { menyampaikan beberapa } \\
\text { evaluasi, kesan, dan pesan pada } \\
\text { akhir kegiatan penyuluhan seni. }\end{array}$ \\
\hline
\end{tabular}

Berikut adalah foto kegiatan dari penyuluhan seni di kelompok Seni Ngudi Laras.

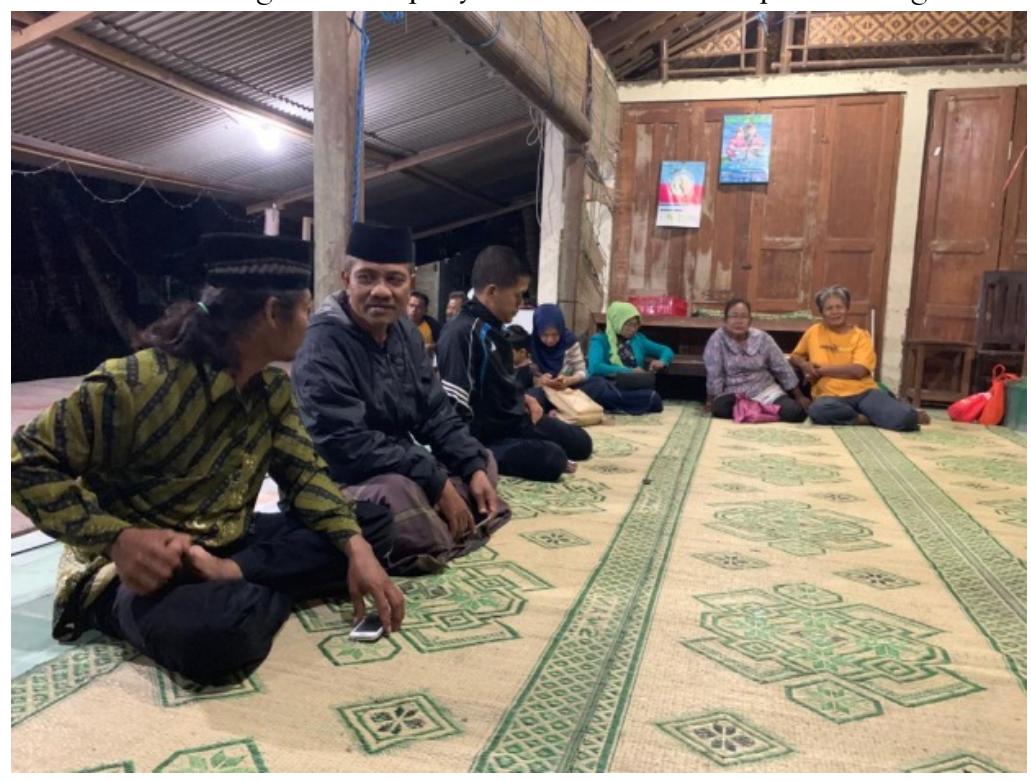

Gambar 1 Diskusi Bersama Peserta Kelompok Seni Ngudi Laras 


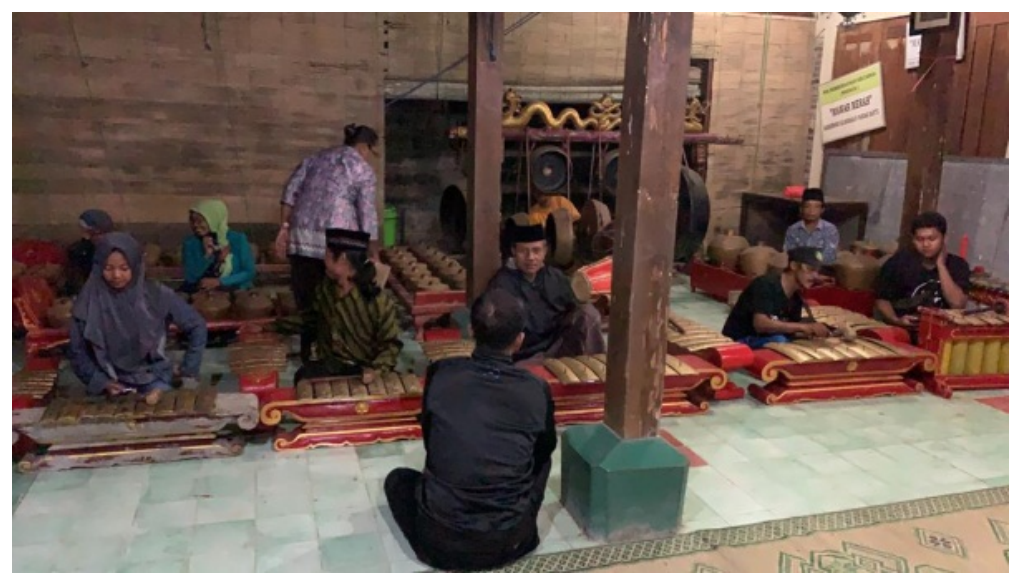

Gambar 2 Kegiatan Persiapan Penyuluhan Seni di Sanggar Kelompok Seni Ngudi Laras

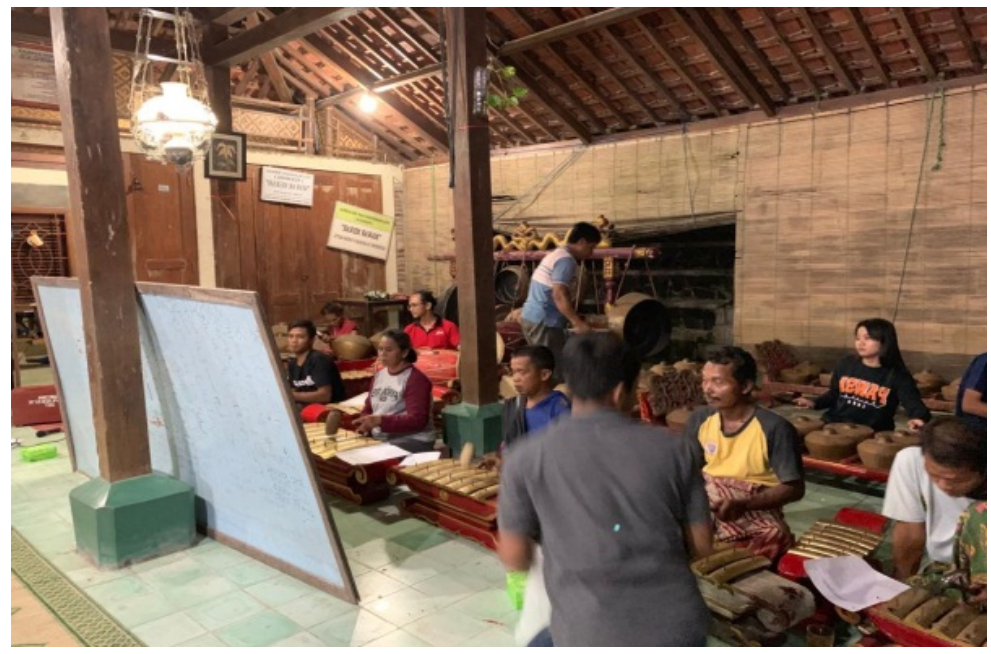

Gambar 3 Proses Penyuluhan Seni di Sanggar Kelompok Seni Ngudi Laras

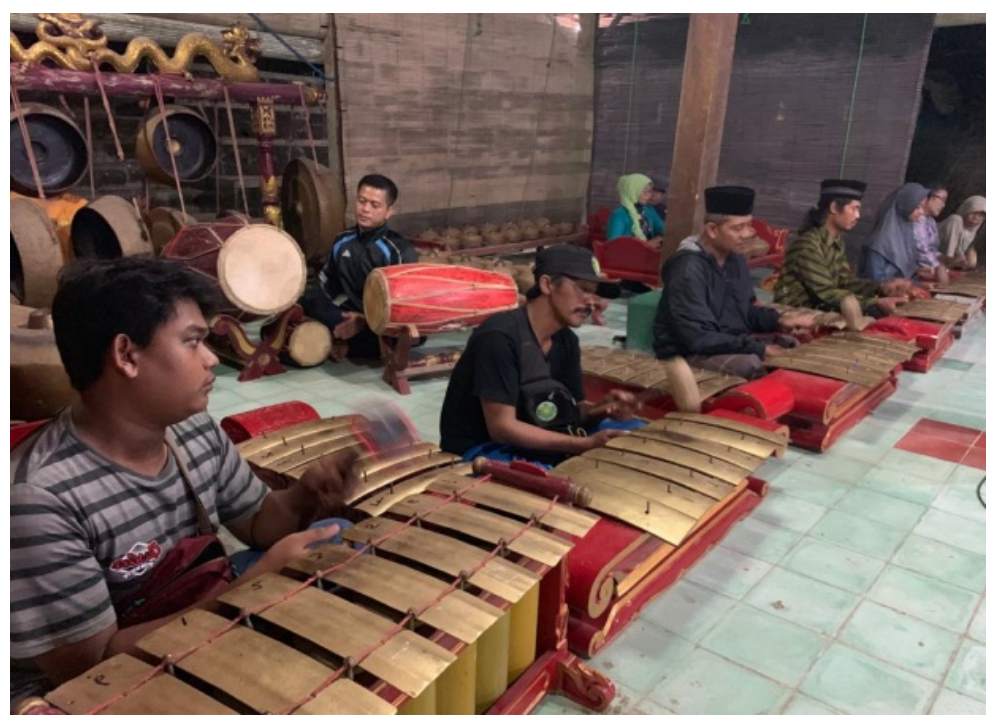

Gambar 4 Proses Penyuluhan Seni di Sanggar Kelompok Seni Ngudi Laras 


\section{Metode Penyuluhan}

Menurut sasaran yang ingin dicapai, penyuluhan seni ini menggunakan metode pendekatan kelompok. Metode penyuluhan langsung sesuai dengan keadaan dan norma sosial dari masyarakat pedesaan Indonesia seperti hidup berkelompok, bergotongroyong, dan berjiwa musyawarah. Metode ini dapat meningkatkan tahapan minat dan perhatian ke tahapan evaluasi dan mencoba menerapkan rekomendasi yang dianjurkan.

$$
\text { Menurut Sulistiani (2002), }
$$
pemberdayaan merupakan sebuah proses menuju berdaya, atau proses untuk mendapatkan data atau kekuatan atau kemampuan dari pihak yang memiliki daya kepada pihak yang membutuhkan kekuatan atau daya. Usaha pengabdian merupakan usaha yang berdampak positif terhadap sosial, perilaku, dan budaya. Penyuluhan seni pada Kelompok Seni Ngudi Laras secara langsung menerapkan keilmuan dan keilmuan yang dimiliki kepada peserta penyuluhan seni.

Kamil (2011) menekankan bahwa pemberdayaan bertujuan mengaktifkan masyarakat melalui kesenian gamelan, adanya kolaborasi dan pengelolaan diri dengan menguatkan keaktifan seluruh anggota kesenian, serta memberikan dampak suasana belajar dengan tumbuh dan berkembang dengan motivasi dalam berperan.

\section{Kendala}

Meskipun penyuluhan dapat dilaksanakan sesuai dengan harapan dan rencana, selama penulis menjalankan penyuluhan seni selama kurang lebih dua bulan, masih ditemui beberapa kendala antara lain: (a) kurang lengkapnya fasilitas gamelan yang dimiliki Kelompok Seni Ngudi Laras, (b) minat anggota sanggar yang masih bersifat fluktuatif dan masih kurangnya kesadaran akan pentingnya upaya pelestarian seni tradisi, dan (c) waktu tatap muka yang cenderung hanya bisa dilakukan pada waktu sore hari dikarenakan kesibukan para peserta penyuluhan sehingga dalam kurun waktu dua bulan masa penyuluhan ini penulis merasa adanya keterbatasan waktu.

\section{Hasil Penyuluhan}

Jumlah peserta penyuluhan yang berjumlah 23 orang telah mengikuti penyuluhan seni mengenai peningkatan mutu pelatih Kelompok Seni Ngudi Laras dengan baik. Berdasarkan hasil evaluasi yang dilakukan, pengamatan prapenyuluhan dan pascapenyuluhan menggambarkan bahwa ada peningkatan kompetensi para pelatih Kelompok Seni Ngudi Laras. Pemahaman dasar seni karawitan yang telah diberikan selama penyuluhan menjadi acuan yang jelas bagi pelatih dalam meneruskan kegiatan pembelajaran menabuh gamelan sebagai rutinitas segenap anggota sanggar.

$$
\text { Indikator lain yang dapat }
$$
menunjukkan adanya keberhasilan penyuluhan seni ini adalah meningkatnya minat peserta dalam berlatih gamelan setelah para pelatih dikenalkan metode pembelajaran yang efektif bagi anggota Kelompok Seni Ngudi Laras. Pementasan gending-gending materi penyuluhan seni yang dilakukan dalam mendukung kegiatan kelurahan Sindumartani dalam rangka Hari Jadi Sindumartani juga menjadi contoh hasil dari keberhasilan penyuluhan seni yang dilakukan selama kurang lebih dua bulan di sanggar Kelompok Seni Ngudi Laras.

\section{SIMPULAN}

Penyuluhan seni dengan tajuk "Kaderisasi dan Peningkatan Kemampuan Pelatih Karawitan di Kelompok Seni Ngudi Laras, Watu Lumbung, Kadiluwih, Salam, Magelang" memberikan penerangan atau informasi agar hal-hal yang tadinya belum diketahui dan belum dipecahkan kaitannya 
dengan problematika di dalamnya agar segera menemukan jalan keluar yang terbaik sehingga kesinambungan aktivitas sanggar tersebut bisa berjalan secara terus-menerus dan mengalami peningkatan yang signifikan.

Dalam penyuluhan selama kurang lebih dua bulan, sedikit pemahaman akan sistem dan perubahan pada individu serta masyarakat Kelompok Seni Ngudi Laras dapat lebih disadari sehingga ke depannya dapat terwujud perubahan yang lebih sesuai dengan apa yang diharapkan sanggar itu sendiri.

Memberdayakan dan memperkuat kemampuan Kelompok Seni Ngudi Laras melalui proses belajar bersama yang pertisipatif, agar terjadi perubahan perilaku pada diri setiap individu dan masyarakatnya untuk mengelola kegiatan yang semakin produktif dan efisien, demi terwujudnya kehidupan sanggar yang lebih baik dan sejahtera secara berkelanjutan.

\section{SARAN}

Kegiatan penyuluhan yang merespons kebutuhan masyarakat seperti ini perlu terus ditingkatkan kedepannya. Potensi sumber daya masyarakat di sektor seni dan budaya merupakan wahana yang harus terus ditingkatkan pelayanannya bagi kalangan lembaga pendidikan tinggi /akademisi demi kemajuan masyarakat, bangsa dan negara.

Kerja sama antara LPPM ISI Yogyakarta, sanggar, dan pamong desa setempat seyogianya diperluas cakupan dan jaringannya sehingga kemandirian masyarakat dalam mengembangkan potensi seni dan budaya sesuai dengan karakter daerah masingmasing dapat berlangsung secara berkesinambungan.

\section{UCAPAN TERIMA KASIH}

Penulis mengucapkan terima kasih kepada pihak LPPM ISI Yogyakarta yang sudah memberikan fasilitas adanya program penyuluhan seni dan kepada Kelompok Seni Ngudi Laras yang telah bekerja sama dengan baik selama proses pelaksanaan penyuluhan seni. Terima kasih juga kepada pihak-pihak terkait yang mendukung kegiatan sehingga kegiatan penyuluhan seni berjalan lancar.

\section{DAFTAR PUSTAKA}

Sulistiani, Ambar Teguh. (2004). Kemitraan dan Model-Model Pemberdayaan. Yogyakarta: Gala Media.

Sugiyono. (2012). Memahami Penelitian Kualitatif. Bandung: CV Alfabeta.

Kamil, Mustofa. (2011). Pendidikan Non Formal Pengembangan Melalui Pusat Kegiatan Belajar Masyarakat (PKBM) di Indonesia (Sebuah Pembelajaran dari Komikan di Jepang). Bandung: Alfabeta. 